\title{
Standard Deviation
}

National Cancer Institute

\section{Source}

National Cancer Institute. Standard Deviation. NCI Thesaurus. Code C53322.

A measure of the range of values in a set of numbers. Standard deviation is a statistic used as a measure of the dispersion or variation in a distribution, equal to the square root of the arithmetic mean of the squares of the deviations from the arithmetic mean. 